\title{
A morte especulativa de Deus: religião e história à luz da primeira crítica sistemática de Hegel em Jena
}

\author{
The speculative Death of God: Religion and History in light of \\ Hegel's First Systematic Critique in Jena
}

Luiz Filipe da Silva ${ }^{1}$

\begin{abstract}
RESUMO: Pretende-se oferecer um relato preciso acerca da função sistemática, e assim especulativa, que as críticas de Hegel aos rebentos culturais do Esclarecimento, compreendidos sistematicamente como manifestações, possui no constructo de seu pensamento. Para isso, elencaremos em Fé e Sabere na Differenzschrifto conjunto de elementos culturais e filosóficos que pendiam para destituição do papel da religião de acordo com o antigo modelo e como, com base no anúncio hegeliano a respeito da "morte de Deus", será possível a partir de um processo histórico-filosófico recalcitrante apresentar a tendência especulativa à unidade
\end{abstract}

PALAVRAS-CHAVE: Deus; Hegel; Esclarecimento; Morte; Fé e Saber; Differenzschrift.

ABSTRACT: It is intended to provide an accurate account of the systematic, and thus speculative, function, that Hegel's criticisms on the cultural sprouts of Enlightenment, systematically understood here as manifestations, has within the construct of his thought. In order to do this, we will establish in Faith and Knowledge and in Differenzschrift the set of cultural and philosophical elements that hung to remove the role of religion accordingly to the old modeland how, based on the Hegelian announcement concerning the "death of God", is possible from a recalcitrant historical-philosophical process to present the speculative tendency to unity.

KEYWORDS: God; Hegel; Enlightenment; Dead; Faith e Knowledge; Differenzschrift.

\section{Considerações iniciais}

A maioria dos relatos da época revelam que a entrada de Hegel na cena filosófica, a partir de 1801 em Jena, não poderia ter causado maior impacto. Com o golpe de estreia, sem pestanejar, ele apresenta uma posição peremptória, e, certamente, a mais bem desenvolvida até então, acerca de uma controvérsia que se arrastava desde a década passada, e que mesmo seus atores não pareciam estar aptos a resolver, isto é, sobre a verdadeira relação entre as filosofias de Fichte e Schelling. O tema da controvérsia, eivado pela conclusão que Hegel ajuíza, foi, então, trazido à luz no título de seu escrito inaugural sob a alcunha de Diferença entre os sistemas filosóficos de Schelling e Hegel. Mas, essa disputa, que parecia consistir em mais uma contenda teórica produzida no interior da filosofia, analisada sistemicamente, se

\footnotetext{
${ }^{1}$ Doutorando em Filosofia pela UFRGS. Mestre em Filosofia pela UFJF. Contato: luizfilipe3r@gmail.com
} 
revelava enraizada profundamente na fissura aberta por uma tendência que se alastrava na cultura, colocando em risco o valor e o espírito de diversas manifestações da vida humana. Além de um relato estritamente teórico, as produções de Hegel em Jena, principalmente aquelas publicadas no KritischesJournal der Philosophieindicavam uma forte preocupação com aquilo que em seus textos se convencionou chamar "Zeitgeist". No entanto, com as vestiduras de um típico sistema pós-kantiano, em contraponto a fixação dos opostos, produzidos pela cultura enquanto manifestação (Erscheinung) que se adsorveu como livre, brotava a "necessidade da filosofia" de construir (konstruirt) o Absoluto, aquela totalidade originária, para a consciência. Doravante, este trabalho tem a pretensão específica de apresentar parcialmente a vinculação necessária entre o diagnóstico de seu tempo, que acreditamos estar centrado principalmente na sua leitura acerca das novas manifestações da tradição religiosa e da visão histórica, objetos da primeira e segunda seção, e a necessidade de desenvolvimento especulativo que brotava daquela cisão, foco específico da terceira parte. Mais especialmente, no que diz respeito a primeira parte de nosso trabalho, articularemos a crítica à visão religiosa dos novos tempos com a necessidade de reformulação metafísica a respeito da questão de Deus. A segunda parte será dedicada à crítica do historicismo e fundamentação de uma metafísica do processo histórico-espiritual. A terceira, como acabamento, buscará derivar disso, a função sistemática da crítica, de modo que, para Hegel, seja dada na história, a gênese e o desenvolvimento de Deus, ou Absoluto, que se reconstitui especulativamente em cada manifestação como a própria razão.

\section{A religião dos novos tempos}

É impossível adentrar na especificidade do pensamento de Hegel em tal período sem conceder as devidas atenções aos diagnósticos críticos que brotam da sua tentativa de conciliação sistemática entre uma postura teórica-filosófica com a crítica histórico-social. Por isso, não se pode alegar ao acaso o fato de que Hegel foi o primeiro filósofo a formular sistematicamente uma validade precisa para o conceito de modernidade. Tal conceito teve de ser preenchido por uma série de novos eventos, conteúdos, e uma carga espiritual muito particular. Talvez o principal exemplo seja a irrupção da noção de uma "consciência de época". Com ela brota, principalmente a partir dos eventos arrolados no processo de esclarecimento do século XVIII, um ideal de autonomia que, em detrimento de tudo aquilo que a humanidade havia produzido, pregava o desligamento da normatividade do passado. 
Esquecia-se, contudo, que o custo de toda autonomia é a necessidade de arcar com as responsabilidades que dela advém. Da sua grosseira tendência pela oposição, Hegel, então, apresentava-se como delator.

Já no primeiro parágrafo de Fé e Saber Hegel dá o tom e revela prontamente esta função. Suas notas iniciais demarcam bem o papel que coube à filosofia e à religião derivadas do problemático processo de desenvolvimento das ideias que o Esclarecimento estabeleceu. Hegel quer mostrar que mesmo a "antiga oposição entre filosofia e religião positiva" (HEGEL, 2009, p.19), em tempos atuais, já não poderia ser tomada seriamente, em sentido estrito, uma vez que a força viva que antes habitava tais esferas já não tinha razão de ser. Neste processo, nem as contendas de uma contra a outra, e nem mesmo as interações positivas, seriam capazes de restabelecer tal vivificação. A "razão esclarecida" - que Hegel alertava ser "diferente daquilo a que se atribui esse nome" - na pretensão do esclarecimento, legou às duas uma condição estéril em que, nem a razão permaneceu razão estritamente, nem o positivo prevaleceu como religião. $\mathrm{O}$ entusiástico discurso de delimitação de suas possibilidades havia sido responsável por aquela deformidade enfrentada. Mantiveram-se suas formas, mas seus espíritos haviam sido dominados e diluídos diante dos preceitos deste novíssimo e determinante espírito.

Da mesma maneira que a religião daqueles tempos, conexa com pietismo e o subjetivismo, devido ao iminente risco do entendimento, recluía-se na experiência interior, a cognição filosófica dos "novos tempos", tal qual se apresentou em Kant, Jacobi e Fichte, se relacionava com o absoluto. Tal como naquele modelo de religião, estas filosofias adotavam a subjetividade reflexiva como ponto chave de seus projetos. As posições multifacetadas desta tríade filosófica esclareciam que o modelo operado pela reflexão não se manifestava de modo particular num determinado grupo, mas se encontrava, em geral, como tendência, arraigada na forma de se fazer filosofia em seu tempo.A exposição de Hegel deixa isso bem claro quando enfoca mais detalhadamente nas diferenças do que nas similitudes de cada uma.

As posições que essas "formas" compartilhavam em seu âmago são muito bem definidas. Todos os três modelos de filosofia apresentados, a saber, kantiano, jacobiano e fichteano, se ancoravam naquilo que Hegel entendia como "modelo dualista" do conhecimento, ou seja, se baseavam na oposição entre um sujeito cognoscente e um conteúdo disposto independente dele. Nesta relação, ambos, sujeito e objeto, permanecem distintos absolutamente. No ato do conhecimento, o sujeito servia como mero molde formal para um objeto previamente dado. Este modelo era especificado como "modelo reflexivo", pois tinha como fonte formal do conhecimento a faculdade do entendimento, que em sua operação 
tendia a conceitualizar apenas o material empírico em sua finitude. ${ }^{2}$ Faltou-lhes a percepção que o absoluto (infinito) necessariamente tem que ser entendido como a identidade do finito e do infinito, mesmo na permanência de um e outro enquanto tais, ou, como disse Hegel numa outra oportunidade, como a "identidade da identidade e da não-identidade".

O que elas tinham em comum com a religião era o modo de relação indiferente para com Deus. Um modo de relação unilateral que perpassa e constitui o ideal de uma modernidade que, fincada no "progresso", se mantinha peremptória a respeito de suas concepções. Vejamos:

Segundo Kant, o supra-sensível é incapaz de ser conhecido pela razão, a ideia suprema não tem simultaneamente realidade. Segundo Jacobi, a razão se envergonha de mendigar, e para cavar ela não tem nem mãos nem pés, ao homem é dado apenas o sentimento e a consciência de sua ignorância do verdadeiro, apenas o pressentimento do verdadeiro na razão, a qual é tão-somente instinto e algo subjetivo. Segundo Fichte, Deus é algo inconcebível e impensável, o saber não sabe nada senão que ele sabe nada e deve buscar refúgio na fé (HEGEL, 2009, p.20).

O que havia acontecido foi que com Kant, Jacobi e Fichte, o Esclarecimento havia chegado a percepção de sua própria negatividade. Entretanto, ao passo que havia sido quebrada toda bela alma do mundo, a inação que os novos tempos tinha produzido havia chegado a essas formas e, desta forma, sua consciência percebido que se tornara mero conhecimento finito, desejante de uma realidade distante de suas possibilidades.

Aquele modelo de religião, que, como aponta Dreher (2003, p.78),foi dado início a partir de uma forte "ênfase na obra de cristo e na hermenêutica bíblica, e com um certo apelo à experiência interior",instaurava no coração do homem a busca pela realidade divina, mas suas condições, à mercê dos perigos do entendimento, consistiam de adornos frívolos e pouco efetivos na caçada ao divino. Isso representava uma tentativa de "fuga" que se operava graças a mesma ameaça, representada pelo entendimento e sua cognição coisificadora. Seu lado sublime consistia, em oposição à mania de finitude desta cognição, na sua busca por um absoluto e uma eternidade não adquiridos pelo olhar, ou seja, na sua não dependência de uma “intuição ou deleite passageiro". O seu anseio, que devido a sua natureza irrealizável se

\footnotetext{
${ }^{2}$ Nesta comunhão de três formas uma nova divisão era apresentada. A filosofia da subjetividade reflexiva deve ser dividia numa ordem bipartite. A filosofia de Jacobi se contrastava da de Kant e Fichte, ainda que esta diferença entre o "realismo" do primeiro e o "idealismo transcendental" dos subsequentes se apresentasse como meras gradações no interior do mesmo modelo filosófico. Elas dizem respeito sobre como o "Eu" vai ser entendido. No modelo jacobiano o si mesmo é visto como mais uma determinação no interior de tantas outras. No modelo transcendental o "Eu" é entendido excluído de toda diversidade, seja através de um sujeito vazio e enclausurado (Kant), ou de um Eu oposto a toda determinação (Fichte). Nesta diferenciação algo novo se apresentava. Hegel percebe o avanço que o idealismo transcendental possui em relação ao realismo. Onde Jacobi enxergava uma multiplicidade de determinações finitas, Kant e Fichte percebem a persistência do "lado negativo" que o infinito carrega.
} 
transformava num anseio infinito, que se pautava pela beleza e bem-aventurança eterna, só poderia ser algo subjetivo. Se fosse trazido à objetividade se completaria ganhando a forma de uma essência mundana, isto é, coisificada. Nunca penetrava na coisa mesma, mas mantinha-se no ponto de vista da distância primordial. Desta forma, a religião, como sentimento, fugiria da mancha carregada pela objetividade, apostando como via para o supremo deleite a idealidade oposta a sensibilidade. ${ }^{3}$ Neste sentido, Hegel chama a atenção para o modelo unilateral deste tipo de relação. O sentimento interior, a intenção, e a crença que eram pregados permaneciam enclausurados e não chegavam na realização de seu objeto. Como diz Hegel (2009, p.22) sua existência carecia de exteriorização, isto é, precisavam vir à ação e à objetividade enquanto "pensamentos, conceitos e palavras". 4

A próxima operação, típica de uma consciência movida pela subjetividade reflexiva, só poderia ser transferir aquela oposição para o campo da empiricidade. "Depois de chegado o tempo" (HEGEL, 2009, p.23), cansada de se opor idealmente ao seu anseio, não elevando a empiricidade à união com a idealidade, pela necessidade de se objetivar, aquela consciência agora rebaixa-se ao nível da sensibilidade.O que Hegel tematiza, desta forma, seria aquela má reconciliação em que a razão, sem saber, havia se conformado que é puro entendimento e havia se entregado àquela realidade sem o mínimo pudor. Nesta operação, para de fato sentirse reconciliada com a realidade ordinária necessitava estar justificada numa boa consciência moral onde poderia emergir na realidade empírica com confiança e sem nenhum pecado. A doutrina da bem-aventurança se instaura de modo que agora, pela finitização da subjetividade, o sujeito empírico crer ter se reconciliado com a realidade ordinária. Aquela subjetividade religiosa, que Hegel indica como sendo a "bela subjetividade do protestantismo", que diante do perigo de se dessacralizar graças ao risco do entendimento, ou melhor, que na iminência de perder sua pureza se preservava subjetivamente, pelo caráter do eudemonismo (bem-aventurança empírica) e do Esclarecimento (entendimento), foi convertida numa "subjetividade empírica".

Qual seria a relação desse caráter com as filosofias de Kant, Jacobi e Fichte? Hegel diz que essas, em sua direção consciente, se dirigem propriamente contra o princípio do eudemonismo. Cabe ressaltar aqui a precaução da ética do dever kantiana com todo tipo de deleite empírico, a rigidez da ética de Fichte, que foi chamada de fanática por Schelling em

\footnotetext{
3“'A 'bela alma', que ainda não havia sido mencionada expressamente aqui, é tanto um exemplo disso quanto o giro de Jacobi contra o "materialismo religioso"' (JAESCHKE, 2006, p.128).

${ }^{4}$ Desta mesma necessidade carecia a arte. Ela, na tentativa de se exteriorizar acabaria se tornando mera coisa. No entanto, esse poder de fuga do finito "é tanto um lado necessário quanto esforçar-se contra ele" (HEGEL, 2009, p.22). No receio de se objetivar, ela poderia cair no erro de enclausurar-se, transformando o belo em "coisas em geral" e, assim, os ideais em ficções.
} 
1802, e a aparente recusa de Jacobi à razão do Esclarecimento. No entanto, Hegel quer mostrar que "permanece nessas filosofias o ser absoluto do finito e da realidade empírica e a contraposição absoluta do infinito e do finito, e o que é ideal é compreendido apenas como conceito" (HEGEL, 2009, pp.26-27). No ato do conhecimento, quando o que está em relação se põe positivamente, cria-se uma "identidade relativa" onde objeto, algo real e finito, se torna objeto de conhecimento. Quando a relação é negativa e o objeto não corresponde com a disposição empírica daquela subjetividade regida pelo entendimento, por exemplo, quando se busca o absoluto, considera-se essa ocasião como fruto de uma fraqueza natural, vide a Dialética da Razão na Crítica da Razão Pura. Desta forma, neste jogo de finitude absoluta e infinitude absoluta, o absoluto permanece como uma "vacuidade da razão". Para estas filosofias, tomadas sob alcunha de filosofia teórica "o saber mesmo é nada".

Neste movimento elas apenas aperfeiçoaram o eudemonismo. O eudemonismo pregresso, na expressão que foi tomado pelas filosofias onde o empírico era tudo, mais propriamente nas filosofias do empirismo moderno, como diz Hegel, ainda não tinha alcançado a "perfeição da abstração". Ela era entendida de modo que a infinitude não era de tudo oposta a finitude, pois ela se colocava como uma bem-aventurança. A infinitude era preenchida pelo conteúdo da realidade não sendo entendida de modo puro. De modo mais claro, Hegel quer dizer que se olhava para Deus de acordo com o dito de Gênesis 1:26, ou seja, Deus como a matriz na qual o homem foi feito. Desta forma, "por não ser puro, o conceito está em igualdade positiva com o seu contrário, pois aquilo que constitui o seu conteúdo é justamente a realidade", assim, "nenhuma reflexão antecede a contraposição ou a contraposição não é posta objetivamente, nem o empírico é posto como negatividade para o conceito, nem o conceito é posto como negatividade para o empírico, nem o conceito é posto como negativo em si” (HEGEL, 2009, p.27). Agora, diferentemente, com o aperfeiçoamento que aquelas filosofias trouxeram para a causa do eudemonismo, a abstração se instaura de modo que, por ambos os lados, o conceito é pura oposição. Esta oposição é entendida objetivamente, de modo que, "cada uma é posta como algo que não é o outro" (HEGEL, 2009, p.27), ou seja, os contrários, unidade e multiplicidade, são absolutizados.

Há aqui a tentativa hegeliana de apontar o caráter unilateral destas formas de conhecimento que, em sua essência, se desenvolve excluindo a contraposição presente a um dos polos no qual ela está depositada. De um lado, a consciência é pura idealidade que excluía a realidade, por outro, ela é pura realidade e se reconhece somente conforme tal. O movimento pode ser entendido de modo que, quando a infinitude carece de conteúdo, a consciência passa para o outro lado absolutizando a contraposição, isto é, a objetividade; 
quando é a objetividade que carece de idealidade, a consciência fecha-se em si mesma, entendendo a realidade como corrupção de sua essência. Por esta maneira, o dogmatismo do Iluminismo (entendimento) e do eudemonismo (bem-aventurança empírica) não permitia considerar o deleite e a bem-aventurança de modo supremo. A cognição da subjetividade que moldava seus relacionamentos se concebesse um deleite e uma bem-aventurança considerada como ideia, perderia, nesta operação, seu caráter "empírico e contingente". Nunca conseguiria se localizar no ponto supremo da identidade entre realidade e idealidade. Isto ocorre pela mania de absolutizar um dos lados da relação, não se relacionando a partir do ponto de vista da unidade entre eles, isto é, considerando um dentro do outro. Neste movimento, o lado oposto àquele absolutizado é elevado também à face mais rígida de si mesmo, ou seja, quando a consciência crer se respaldar num lado da relação ela eleva o seu oposto à absolutidade. $\mathrm{O}$ que ela não sabe, e o que Hegel quer aqui introduzir em seu projeto filosófico, é a noção de uma mediação especulativa, isto é, que um terceiro, resultante desta unidade, é o "verdadeiramente primeiro". O conceito vazio só poderia se completar na sua contraparte, isto é, na "bem-aventurança empírica", e esta, por sua vez, em sua plenitude, deveria suportar em si toda expressão ideal, e assim, "fazer de tudo algo que não é em si", estando, desta maneira, postos "de modo idêntico na ideia". No modo reflexivo desta subjetividade Deus é aquilo que se encontra fora das capacidades da razão, pois, na realidade sua cognição é movida pela ideia de uma intuição puramente sensível que opera subordinando toda ideia à finitude e o deleite à bem-aventurança empírica.

Ao final do processo, utilizando a metáfora supracitada de Jacobi, cansada de cavar sem mãos nem pés, a condição a que chegara era de plena impotência, e, como o contraponto a este além inalcançável, a realidade empírica, era a única forma possível, o sentimento não poderia ser outro: “a sensação de que Deus ele mesmo está morto" (HEGEL, 2009, p.170).

\section{A instrumentalização da história como mera técnica.}

Pode-se dividir a crítica à visão histórica das filosofias em dois momentos: a primeira é dirigida contra a ideia de que a filosofia seria essencialmente história das ideias no decurso do tempo; a segunda contra a ideia de que a filosofia se aperfeiçoa mediante a descoberta de novas técnicas. ${ }^{5}$

\footnotetext{
${ }^{5}$ Como dissemos, a crítica hegeliana àquilo que o próprio concebia como visão genérica da história, perdurou durante boa parte de sua vida. Vemos ainda o ressoar disso nas suas Lições sobre a história da filosofia, compilada e publicada por seu aluno Michelet, em 1833, como resultado de uma série de cursos dados por
} 
Hegel dedicou no texto uma seção completa voltada para as diversas formas que apareciam no filosofar daqueles tempos. Ela refletia a crítica hegeliana à visão histórica dos sistemas filosóficos. As críticas eram voltadas, em um âmbito maior, para a instrumentalização da filosofia como técnica. A morte do real sentido especulativo que a filosofia pressupõe, parecia brevemente ser anunciada se tais sistemas filosóficos, então em voga, continuassem naquela indiferença absoluta no exercício de seus saberes. Com base na perspectiva de que a filosofia seria a história das ideias no decurso do tempo, "uma época que deixou para atrás de si, como passado, uma tal quantidade de sistemas filosóficos, parece ter chegado até aquela indiferença que a vida obtém após ter-se todas as formas” (HEGEL, 2003, p.33). A crítica estaria voltada, então, contra o olhar distanciado que se manifesta em tal perspectiva. Pelos sistemas filosóficos, esta visão se interessaria apenas como objetos de conhecimento, não dispondo de nenhum vínculo imanente. Tal historicismo aniquilaria todas as possibilidades de investigação do valor essencial presente nas diversas manifestações que em filosofia se apresentou. Assim, de acordo com Hegel (2003, p.33), "na medida em que [esta visão] transforma a ciência em conhecimento, recusou-lhe a participação viva que a ciência requer". A ciência transformada em conhecimento lidaria com o seu objeto de forma indiferente e, assim, pronunciaria somente uma visão ossificada da realidade. Sua atividade apenas se limitaria a distinguir seu objeto, sem que uma aplicação axiológica pudesse intervir em seu método. Nele se apresentaria aquela inanição que impediria a percepção dos sistemas filosóficos como desenvolvimento da verdade. A diversidade era concebida como contradição e, com isso, tal conhecimento não poderia ser realizado em uma ciência propriamente dita. Seu destino seria transformar seu objeto em algo estranho e afirmar, então, a liberdade da indiferença absoluta.

Hegel pretendia chamar a atenção para o fato de que a filosofia, concebida ao modo como a sua essência pressupõe, não poderia ser encarada como mero objeto morto, que, de alguma forma, estaria disponível para uma curiosidade indiferente. A filosofia àquela maneira seria, então, uma "coleção de múmias e o amontoado universal de contingências". Contrário a tal visão, Hegel (2003, p.34) afirma: “o espírito vivo que reside em uma filosofia exige, para

Hegel, principalmente no período de Heidelberg e Berlim. Vejamos: "A prova de que a filosofia é vã desenvolve-se com base em uma concepção genérica superficial da história da própria filosofia: o resultado dessa história não é outro que a aparência dos pensamentos mais diversos e dispares das múltiplas filosofias, opostas umas às outras e que contradizem e se refutam. E esse fato, que não pode ser negado, justifica e até mesmo obriga, aparentemente, a aplicar as palavras de Cristo às filosofias, dizendo: 'Que os mortos enterrem seus mortos e me sigam'. A história da filosofia não seria mais do que um campo de batalha de cadáveres, um reino já existente em indivíduos mortos, fisicamente obsoleto, mas também de sistemas refutados e espiritualmente liquidados, cada um dos quais mata e enterra aquele que precede" (HEGEL, 1995, p. 22). 
se revelar, nascer por intermédio de um espírito semelhante". O que se pretendia afirmar, no caso, era que o conhecimento do espírito vivo que abarca cada filosofia só poderia ser compreendido com base um outro espírito vivo. O que se faz valer desta assertiva é que a filosofia, em si mesma, é dotada de vida e o reconhecimento desse processo só poderia ser assimilado pela vivacidade de seu caráter. Seria sintomático que uma época que prezasse pela instrumentalização da filosofia como técnica, chegasse aquela indiferença e inação que Hegel acusa.

\begin{abstract}
Nenhum sistema de filosofia se pode subtrair a possibilidade de um tal acolhimento; cada um é susceptível de ser tratado de um ponto de vista histórico. Tal como cada figura viva pertence, ao mesmo tempo, ao fenômeno, assim uma filosofia, como fenômeno, se entregou aquele poder que a pode transformar numa opinião morta e, desde o começo, em passado. O espírito vivo que reside numa filosofia exige, para se revelar, nascer por intermédio de um espírito semelhante. Ele passa diante da conduta histórica, que resulta de qualquer interesse pelo conhecimento de opiniões, como um fenômeno estranho, e não revela o seu íntimo. Pode-lhe ser indiferente o facto de servir para engrossar a restante coleção de múmias e o amontoado universal de contingências, pois ele próprio escapou ao colecionar curioso de conhecimentos disponíveis. Este agarra-se a sua tomada de posição indiferente a verdade / e mantém a sua independência, quer aceite quer recuse opiniões, quer se mantenha indecidido; com os sistemas filosóficos, não pode ter qualquer outra relação senão a de considerá-los opiniões, e tais contingências como opiniões não lhe podem fazer mal algum; ainda não reconheceram que a verdade existe (HEGEL, 2003, p.34).
\end{abstract}

Além da característica mencionada, uma outra, de mesma origem, poderia ser encontrada nas visões sobre a história dos sistemas filosóficos. Esta ganhou força com o desenvolvimento do pensamento de Reinhold. Para tal visão a filosofia seria "uma espécie de arte manual, que se deixaria aperfeiçoar por meio de novos procedimentos técnicos incessantemente descobertos" (HEGEL, 2003, p.34). Assim, a filosofia caminharia historicamente em um desenvolvimento contínuo e progressivo. Isso se daria, cada vez, mediante as descobertas sucessivas de avanços de maior abrangência que um sistema realizaria em detrimento de um outro, já ultrapassado. Sendo assim, cada sistema, particularmente, buscaria preencher as lacunas do conhecimento que um outro, arcaico, não conseguiu. Não se trata aqui de, como no modelo anterior, partir de uma curiosidade despretensiosa sobre os sistemas filosóficos. Todavia, Hegel enxerga sua precariedade presente no aperfeiçoamento técnico que tal visão pressupunha. Seguindo a instrumentalização do passado histórico dos sistemas filosóficos, essa visão, no momento em que considerasse realizada, definitivamente, a tarefa primordial da filosofia, olharia para o passado somente como "exercícios preliminares para grandes cabeças". Melhor dizendo, a história serviria apenas como instrumento para a realização daquilo que considerasse positivo para a realização plena do conhecimento. Por isso, no passado só havia valor inerente até o 
momento em que ainda não tivessem sido cumpridas todas as exigências que o conhecimento verdadeiro careceria. ${ }^{6}$

Em seu texto, Hegel atribui a Reinhold a busca histórica de uma descoberta definitiva, ou seja, de "um último procedimento técnico universalmente válido". A discussão de Hegel com Reinhold estava voltada majoritariamente pelas polêmicas levantadas por este nos Beiträgede 1801. Contudo, pode-se claramente fazer um paralelo entre as críticas de Hegel e o projeto de filosofia que Reinhold em sua carreira se propôs a divulgar. Reinhold expressamente em suas Briefeüber die KantischePhilosophie (cartas publicadas entre os anos de 1786 e 1787) e também no seu famosos Beyträgezur Berichtigungbisheriger Missverständnisse der Philosophen, de 1794, havia exaltado a filosofia kantiana como o resultado enriquecido do desenvolvimento de todas as outras e, assim, a sua própria como responsável pela descoberta do princípio último em filosofia, do qual todos os outros são derivados. Para uma melhor compreensão deve-se atentar para o fato de que Hegel não está criticando toda análise histórica do desenvolvimento filosófico. O que ele critica unicamente é certa versão deste tipo de análise. O que para Hegel foi relevante em destacar Reinhold dos demais que isso propuseram, praticamente todo o Idealismo alemão, foi o fato deste partir de um método lógico-dedutivo e estar completamente distante do método especulativo de compreensão que Hegel na Differenzschrift estava propondo. ${ }^{7}$ Como evidencia Werle (2012, pp.110-111): "Hegel está apontando para a própria essência da filosofia, que não pode se fixar nesse ou naquele sistema particular ou mesmo se apresenta como continuidade de um determinado sistema, o de Kant, tal como pensava Reinhold”.

Da mesma forma, Hegel alertava para não se confundir pontos de vista próprios com a essência da filosofia. Segundo Hegel, "aquilo que é próprio de uma filosofia, por ser próprio, só pode pertencer à forma do sistema, não a essência da filosofia" (HEGEL, 2003, p.35). Ressalta-se que a filosofia mesma não representa, em si, os atributos presentes e que constituem um sistema filosófico. Antes, "reside nela mesma toda sua obra e sua atividade",

\footnotetext{
6 “Cada nova descoberta pressupõe o conhecimento dos procedimentos já utilizados e dos seus objetivos; mas, após todos os melhoramentos feitos até ao presente, permanece ainda a tarefa fundamental, que, depois de todos os outros, Reinhold parece pensar como a descoberta de um último procedimento técnico universalmente válido, por meio do qual, para todos os que fossem capazes de o conhecer, a obra se realizaria por si mesma. Se se tratasse de fazer uma tal descoberta e a ciência fosse a obra morta da habilidade alheia, caber-lhe-ia, certamente, aquela perfectibilidade de que são capazes as artes mecânicas, e, em cada época, os sistemas filosóficos anteriores não deveriam ser considerados senão como exercícios preliminares para as grandes cabeças" (HEGEL, 2003, pp. 34-35).

7 Conforme Werle (2012, p.112), "temos dois lados da filosofia de Fichte, os quais Reinhold, porém, desconhece". Um deles era aquele que Hegel criticava, isto é, a transferência da unidade especulativa para o âmbito finito da consciência pura, e o outro lado "é o estabelecimento do conceito da razão e da especulação, e com isso torna-se possível a verdadeira filosofia. Fichte encontrou o núcleo, a identidade das diferenças".
} 
ou seja, ela deve ser tomada como "razão que se dirige e se conhece a si mesma" e assim produz uma verdadeira filosofia. A passagem mencionada define e torna mais claro o objetivo hegeliano.

Contra o olhar meramente catalogador ao passado, bem como contra a sua instrumentalização como simples técnica, o que estava presente ao fundo da crítica hegeliana seria a inauguração de seu projeto de valorização do caráter histórico das filosofias. Para tanto, seria necessário diferenciar o tipo de historicismo que se encontrava naquela época. $\mathrm{O}$ objetivo de sua crítica pode ser compreendido como uma tentativa de se pôr como antípoda deste nocivo modo de compreensão histórica dos sistemas filosóficos. Isto se justifica quando Hegel afirma: "Nenhum sistema de filosofia se pode subtrair a possibilidade de um tal acolhimento; cada um é susceptível de ser tratado de um ponto de vista histórico" (HEGEL, 2003, p.34). E assim adiante: “O verdadeiramente próprio de uma filosofia é a individualidade interessante, na qual a razão organizou para si mesma uma figura, com os materiais de uma época particular" (HEGEL, 2003, p. 36).

Em detrimento do estado no qual a filosofia caminhava em seu tempo, para Hegel, seria necessário compreender o desenvolvimento dos sistemas filosóficos como "razão que se dirige e se conhece a si mesma". Seria oportuno perceber, na manifestação histórica dos sistemas filosóficos, o caminho em que a razão "se reconstrói novamente a si mesma como identidade". Assim, se valorizaria o percurso no qual ela veio a si mesma em sua manifestação progressiva, figurada nos sistemas filosóficos. O que faria com que fosse diferenciado por completo do modelo de visão histórica que Hegel havia denunciado. Em primeiro lugar, o passado é vivo e, com isso, não poderia ser meramente catalogado e objeto distante para um "curioso espectador" do conhecimento, ou, muito menos, ser "exercício preliminar para grandes cabeças". A história deveria ser compreendida como manifestação do absoluto e sua real atividade compreendida como "o absoluto que se põe a si mesmo como uma totalidade objetiva" (HEGEL, 2003, p.39). Diante disso, o recurso historicista, em seu verdadeiro sentido, não poderia se apossar dos acontecimentos históricos em sua aparência peculiar. Seria preciso buscar antes a compreensão do fato acontecido partindo de um ponto de vista holístico, considerando o todo em suas vivas inter-relações.

A partir disso, prescreve-se peremptoriamente, como diz Kimmerle (2004, p.18), que, para Hegel, "filosofia não tem história, sua tarefa é a mesma em todos os tempos". Devido a esse caráter não histórico da filosofia, Hegel pode falar de um método filosófico perene, que precede todo saber, ou seja, que representa a tarefa primordial da filosofia em todas as suas manifestações históricas, isto é, a aniquilação das oposições e a construção do absoluto para a 
consciência. Assim, historicamente, por mais que a filosofia seja apresentada sob múltiplas maneiras nas diversas eras, pode-se dizer que, historicamente, a mesma tarefa que ela manifestava antes ela manifesta agora. O que se altera é o refinamento e a força da oposição que se alastra na cultura. Exatamente por esse caráter a crítica da modernidade ocupa uma função sistemática.

\section{A função sistemática da crítica}

Diante do diagnóstico pouco animador que Hegel apresenta, havia uma realidade a ser enfrentada, a saber, a rigidez do entendimento que perigosamente colocava em risco toda tentativa de busca da verdade idealmente, e instaurava uma condição onde o absoluto era visto como uma vaguidade indistinta. Exatamente nestes tipos de conhecimento se apoiaram as filosofias de Kant, Jacobi e Fichte. Diante desta condição, a filosofia não possuía os meios para estar na posse da verdade que havia sido transposta para um além inflexível. Ela teria que aceitar sua condição reconhecendo que se tornou refém de uma fé cega. Hegel sabia que estava fadada a uma versão corrompida, que verdadeiramente valia como a própria morte de sua essência. A absolutez do empírico que reinava nos rebentos filosóficos do Esclarecimento possuía uma efetividade ordinária e trazia à esfera objetiva uma realidade estanque.

Conhecendo o modo como opera a consciência reflexiva, de passagem, uma certa relação com aquilo que Hegel apresentou mais tarde na Fenomenologia do Espirito se mostra manifesta. Ali, a autoconsciência, entendida como aquela que enxerga o mundo como o espelho de si, também aparece como autodeterminante e livre de toda corrupção de um mundo objetivo. No entanto, Hegel demonstra a impossibilidade daquela consciência de se reconciliar consigo mesma. Enquanto ela permanecesse fechada e se mantivesse numa relação negativa com toda determinação, não chegaria à verdade de si. Isto corresponde de forma direta com o modelo de consciência que se apresentou no idealismo transcendental de Kant e Fichte. Esta consciência se mantinha apenas no nível da "certeza de si mesma", ainda não se constituía como "saber efetivo", ou seja, não se realizava objetivamente. Ela ainda não reconhecia sua expressão numa representação objetiva, ou seja, o seu modo era meramente excludente. Na esteira desta tendência, havia se levantando a maioria das contraposições, onde a consciência se relacionava negativamente com tudo que não era si mesma.

Não obstante, a aparição do tema da "morte de Deus" no texto hegeliano não é gratuito e exige um esforço de compreensão que ultrapassa o lugar comum da mera análise do problema da religião a partir do tratamento iniciado por Kant - caminho que o próprio Hegel 
trilha - e da comparação com as leituras mais recentes sobre o tema, principalmente as de Nietzsche e Heidegger. Embora em Hegel o tema da morte de Deus referencie a ideia de um esvaziamento dos temas da metafísica, ele não é guiado num sentido metafórico, mas sim ontológico. Entender isso, como Dreher (2003, p.83) bem percebe, exige uma orientação pela situação histórico-teológica da manifestação do conceito da divindade em meio ao circuito teológico reformado em desenvolvimento a partir do séc. XVII. Grosso modo, dentre outras coisas, esta exigência remete à compreensão de uma ideia básica gestada no seio da heterodoxia luterana. A heterodoxia quenótica, impulsionada pela possibilidade divina de esvaziar-se e padecer das mesmas restrições humanas, tal como aparece em Filipenses 2.5-11, deu as condições, assim, "para pensar filosoficamente a temporalidade e a transformação radicais no conceito e na essência da divindade", onde, "o divino mesmo pode modificar-se, entrar no tempo de maneira 'séria', até a morte, e, quem sabe, no futuro, sem retorno" (DREHER, 2003, p.84).

Neste processo, o próprio Logos, feito carne na pessoa de Cristo, saiu de si. Pode-se falar então de uma reatualização onde Deus se aliena (Entäusserung) num processo de autodiferenciação. Isto, por si só, só faz sentido dentro de uma versão vivificada e processual do próprio Logos. Neste sentido, da mesma maneira que o papel de Deus na gênese do mundo só pode ser imanente, é mister falar, então, de sua morte como um capítulo interno e especulativo da vida divina que se manifestava nas diversas determinações do tempo histórico. O que poderia soar um tanto quanto heterodoxo em face do escolasticismo protestante.

Tanto em Fé e Saber, quanto na Fenomenologia, o método especulativo já tinha se apresentado ao pensamento hegeliano. Na segunda, para se libertar de suas amarras, cabia à consciência desdobrar-se desenvolvendo modos de relação que mantivesse positivamente a síntese entre o objeto e a expressão de si mesma. Na primeira, por mais que a concepção fenomenológica ainda não constituísse o ideário hegeliano, a ideia do saber que inclui a diversidade já se apresentava como contraponto àquelas formas estanques regida pela reflexão.Contudo, ao acusar estas formas, Hegel lançava também sua empreitada filosófica pondo em voga uma discussão que o acompanharia até o final de sua vida. Esta dizia respeito sobre a natureza metodológica a partir da qual se fazia filosofia em seu tempo. Questões tais como, 1) o que é o exercício do filosofar;2) o que ele pressupõe; e 3) quais os seus objetivos últimos, aparecem em grande destaque nas páginas introdutórias da Differenzschrift. Considerando seu esboço sistemático, pode-se responder tais questões dizendo, respectivamente, que o exercício do filosofar deveria ser manifestado pela 1) elevação do 
saber acima de todo conhecimento finito e unilateral;que tal exercício pressupõe 2) a superação das oposições; e que seu objetivo, grosso modo, se satisfazia pela3) construção de Deus para a consciência.

\section{Considerações finais}

Aquilo que na Differenzschrift havia sido apresentado de maneira implícita, a partir de 1802, no opúsculo intitulado Fé e Saber, é evidenciado de modo mais detalhado.Ali, aquela tendência, sob a pretensão de esclarecimento e alegação de emancipação, havia transformado o espírito de uma época em algo rígido, imóvel e sem vida, fixando os opostos uns contra os outros. Destarte, paradoxalmente, devido a este entusiasmo pelo esclarecimento, ela deu forma também a uma multiplicidade de movimentos espirituais, aparentemente distintos, que se aperfeiçoavam ao passo que a rigidez das oposições era asseverada. Em filosofia foi assim com Kant, Jacobi e Fichte que, verdadeiramente, representavam a realização do espírito eudemônico manifesto nas filosofias pregressas de Locke e Hume. ${ }^{8}$ Neste mesmo caminho, tanto a consciência religiosa, aquela bela subjetividade do protestantismo, imaculada pela fuga subjetiva do mundo estabelecida ainda pelos reformadores, foi deflorada pelo espírito dos teólogos do iluminismo, que já não indicava nada mais que uma subjetividade finita.

Tanto em Fé e Saber quanto na Differenzschrift o gênero da crítica filosófica havia alcançado um novo patamar. No primeiro, pode-se dizer que o movimento operado é "intrafilosófico", onde Hegel se esforça em demonstrar a raiz comum manifesta nas filosofias da reflexão da subjetividade. No segundo, ganha espaço a crítica "histórico-cultural" de seu tempo, ressaltando o poder de divisão alastrado no mundo moderno. No entanto, no gradual desenvolvimento de ambos os textos, Hegel intercala seu diagnóstico pouco satisfeito da realidade com um tom propositivo, indicando a necessidade da filosofia se desdobrar em meio aquele deserto anêmico de rigidez epistemológica. $\mathrm{O}$ tom e modo como isso está arranjado não deixa dúvidas sobre o caráter sistemático que as críticas ocupam no projeto filosófico hegeliano. Visam nada mais que elucidar a situação do tempo presente com o objetivo de superar suas contradições. Permanece, então, sistematicamente, ao longo de todo processo, o ímpeto especulativo que conduz os opostos finitos à identidade absoluta, que é exatamente o mesmo que permitirá Hegel,mesmo alegando que "Deus mesmo está morto", reafirmar, sem relegar, o ideal cristão da unidade entre divindade e humanidade.

\footnotetext{
${ }^{8}$ Fichte caracterizava a mais atual expressão daquele espírito, por isso a necessidade de distingui-lo da nova
} filosofia de Schelling. 


\section{Bibliografia}

DE VOS, Lu. EineSystemskizze der Differenzschrift. In: VIEWEG, Klaus. Hegels Jenaer Naturphilosophie. München: Fink, 1998.

DREHER, Luís H. Vida, liberdade e subjetividade religiosa: mapeando um acesso possível à questão filosófica de Deus. In: XAVIER, Maria L. O. (Org). A Questão de Deus. Ensaios Filosóficos. Sintra: Zéfiro, 2010.

A questão da morte de Deus. In: FERREIRA, Acylene M. C. (Org.).Fenômeno e Sentido. Salvador: Quarteto, 2003, p. 73-92.

HEGEL, Georg W. F. Fé e saber. Tradução Oliver Tolle. São Paulo: Hedra, 2009.

- Diferença entre os sistemas filosóficos de Fichte e Schelling. Tradução Carlos Morujão. Lisboa: Imprensa Nacional-Casa da Moeda, 2003.

. Lecciones sobre lahistoría de la filosofia. Tradução Wenceslao Roces. Ciudad de México: Fondo de Cultura Econômica, 1995.

JAESCHKE, Walter. Hegel-Handbuch: Leben-Werk-Schule. 3. Auflage. Springer-Verlag, 2016.

JONKERS, Peter. Philosophische Kritik in Hegels Systemkonzeption von 1801/02.In: KIMMERLE, Heinz. (Org.).Die Eigenbedeutung der Jenaer Systemkonzeptionen Hegels, 2004.

KIMMERLE, Heinz. Das Verhältnis von Philosophieund Geschichteam Anfang der Jenaer Periodedes Hegelschen Denkensunddessenaktuelle Bedeutung In:

Eigenbedeutung der Jenaer Systemkonzeptionen Hegels. Erasmus Universität Rotterdam. De Gruyter, 2004. 2016. Das Problem der Abgeschlossenheitdes Denkes. Hamburg: Feliz MeinerVerlag,

WERLE, Marco Aurélio. O acolhimento hegeliano do pensamento antinômico na época de Jena. Cadernos de Filosofia Alemã: Crítica e Modernidade, n. 19, p. 107-125, 2012. 